\title{
Eggshell calcifications on a routine chest x-ray
}

\author{
William C Green BS, Gilbert Berdine MD
}

\section{CASE}

A 74-year-old man presented with dyspnea on exertion and nonproductive cough. He has had dyspnea on exertion since the 1970s. He is a lifetime nonsmoker. His occupational history is significant for work as a sculptor since 1989, and he was likely exposed to a large amount of fibrogenic particles, such as silica. He also had a history of being exposed to Agent Orange during the Vietnam War. His physical examination and vital signs were unremarkable; laboratory tests, including CBC, CMP, and UA, were normal. Due to his history of dyspnea on exertion and his occupation, an x-ray was obtained which showed bilateral hilar and mediastinal adenopathy with eggshell calcifications (Figure). The patient claims that the unusual appearance of the lymph nodes was discovered after the Vietnam exposure to Agent Orange but prior to his career as a sculptor. Old films are not available to determine whether this eggshell calcification was present when he returned from Vietnam. He underwent evaluation for an abnormal chest x-ray in 1973, but information from that evaluation is not available.

\section{Discussion}

Pneumoconiosis can be either fibrotic or nonfibrotic. Silicosis and coal workers pneumoconiosis are fibrotic diseases and can lead to calcifications of lymph nodes. Chronic silicosis leads to an increase in inflammation and fibrogenic factors. ${ }^{1}$ Eggshell calcification is a radiographic term describing abnormal hilar or mediastinal lymph nodes. According to Fraser and Pare, "Eggshell calcification is uncommon; it consists of a ring of calcification around the periphery of
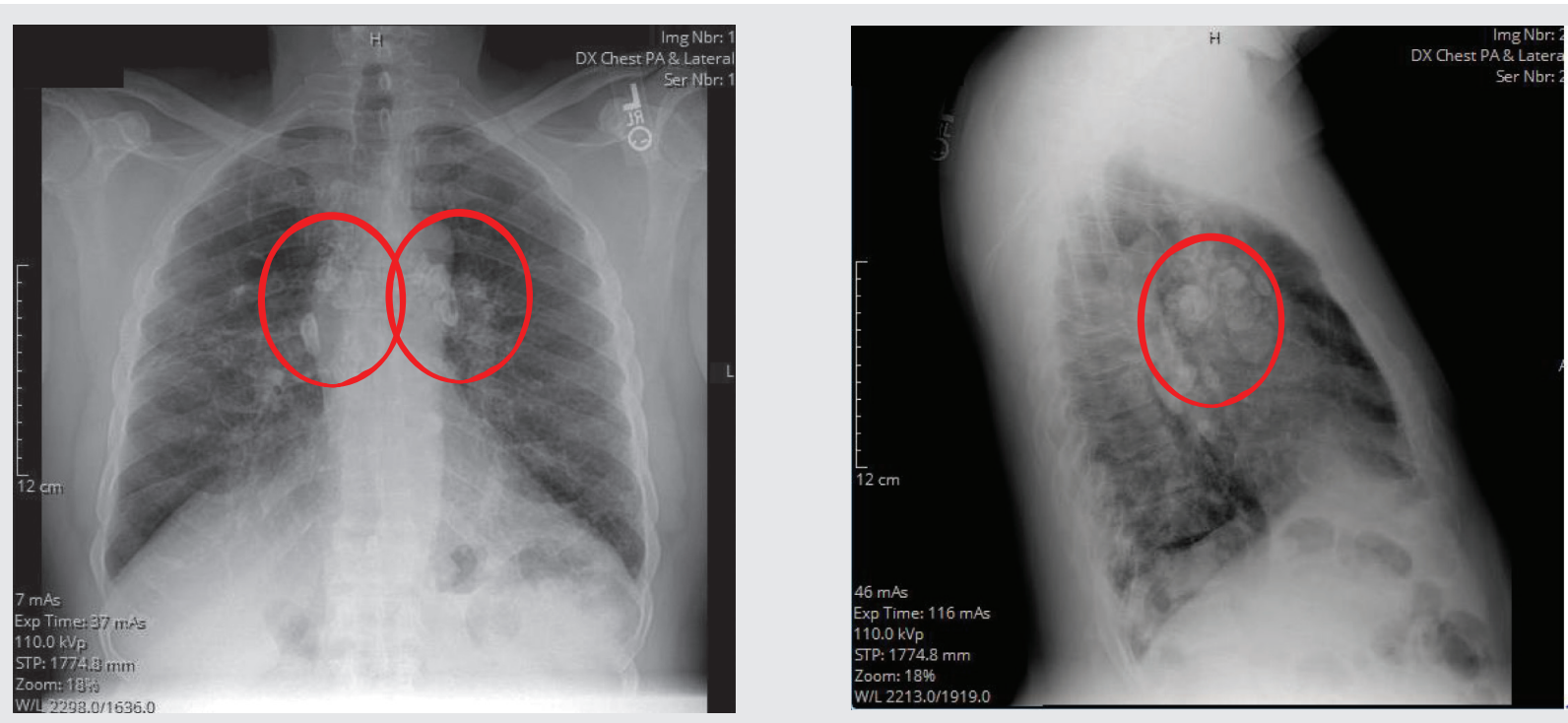

Figure. PA and lateral chest x-rays demonstrate bilateral egg shell calcification of the hilar lymph nodes. See red circles.

Corresponding author: Gilbert Berdine

Contact Information: Gilbert.berdine@ttuhsc.edu DOI: 10.12746/swrccc.v7i27.521 
a lymph node and occurs most typically in silicosis." The chest film of this patient illustrates this finding much better than the textbook does.

Agent Orange is a mixture of two phenoxy herbicides used during the Vietnam War that contained the human toxin, 2,3,7,8-tetrachlorodibenzo-p-dioxin (TCDD), a fat-soluble compound with pro-inflammatory effects. ${ }^{3}$ Dioxins act via an aryl hydrocarbon receptor pathway increasing airway inflammation and decreasing normal immunologic function. ${ }^{4}$ These properties can have an additive effect with other chemicals, toxins, or particles, such as silica, to damage lung tissue. Human exposures to Agent Orange and TCDD have been linked to many deleterious health effects, such as a variety of birth defects, cancers, and other non-malignant respiratory disorders, including chronic obstructive pulmonary disease..$^{5}$ This report of such clear eggshell calcifications could be due to exposure to Agent Orange/dioxin coupled with years of exposure to silica.

Eggshell calcification is non-specific but most commonly occurs in silicosis and coal workers' pneumoconiosis. It can also be seen with post-irradiation lymphoma, sarcoidosis, scleroderma, amyloidosis, and infectious, such as blastomycosis and histoplasmosis. ${ }^{6}$ A thorough history with past environmental exposures can usually identify the most likely etiology. This case highlights the importance of old films to determine the cause of disease. If old films taken after the patient's exposure to Agent Orange in Vietnam but prior to the patient's exposure to silica from sculpting demonstrated the eggshell calcifications, one would have to consider Agent Orange as a possible causative agent. Without these old films, one must consider the silica exposure from sculpting as the likely causative agent.

Keywords: eggshell calcification, silicosis, occupation, Agent Orange

From: The Department of Internal Medicine at Texas Tech University Health Sciences Center in Lubbock, Texas

Submitted: $10 / 10 / 2018$

Accepted: $12 / 20 / 2018$

Reviewer: Eman Attaya MD

Conflicts of interest: none

This work is licensed under a Creative Commons Attribution-ShareAlike 4.0 International License.

\section{REFERENCES}

1. Greenberg MI, Waksman J, Curtis J. Silicosis: A review. Disease Month 2007;53:394-416.

2. Fraser RG, Pare JA. Diagnosis of Diseases of the Chest. 3rd Ed. 1977; Volume 1: $\mathrm{p} 470$.

3. Kerkvliet NI. Immunological effects of chlorinated dibenzo-pdioxins. Environmental Health Perspectives 1995;103(Suppl 9):47-53.

4. Beamer CA, Shepherd DM. Role of the aryl hydrocarbon receptor $(\mathrm{AhR})$ in lung inflammation. Seminars in Immunopathology 2013;35(6):693-704.

5. Bertazzi PA, Consonni D, Bachetti S, et al. Health effects of dioxin exposure: a 20 -year mortality study. Am J Epidemiol 2001 Jun 1;153(11):1031-44.

6. Gross BH, Schneider HJ, Proto AV. Eggshell calcification of lymph nodes: An update. AJR Am J Roentgenol 1980;135: $1265-8$. 